\title{
Mid-Upper Arm Circumference
}

National Cancer Institute

\section{Source}

National Cancer Institute. Mid-Upper Arm Circumference. NCI Thesaurus. Code

C124475.

A circumferential measurement of the largest part of the upper arm. 